\title{
低コヒーレンス光干渉による面内複屈折測定
}

$\begin{array}{llll}\text { 非会員 } & \text { 西 } & \text { 壽巳 } & \text { (大阪工業大学) } \\ \text { 非会員 } & \text { 井上 } & \text { 将吾 } & \text { (大阪大学) } \\ \text { 非会員 満山 } & \text { 照樹 } & \text { (大阪大学) } \\ \text { 非会員 下谷 } & \text { 望 } & \text { (大阪工業大学) } \\ \text { 非会員 芦澤 } & \text { 努 } & \text { (大阪工業大学) } \\ \text { 非会員 丸山 } & \text { 英樹 (九州松下電器) } \\ \text { 非会員 近江 } & \text { 雅人 (大阪大学) } \\ \text { 会 員 春名 } & \text { 正光 (大阪大学) }\end{array}$

\section{Birefringence Measurement by Low Coherence Interferometry}

Hisami Nishi,Non-member, *Shougo Inoue,Non-member, *Teruki Mitsuyama,Non-member, Mozomi Shimotani,Nonmember, Tsutomu Ashizawa,Non-member, **Hideki Maruyama,Non-member, *Masato Ohmi,Non-member, *Masamitsu Haruna,Member , (Osaka Institute of Technology), *( Osaka University), **( Kyushu Matsushita Electric Co., Ltd.)

\begin{abstract}
We proposed and demonstrated a practical method for simultaneous measurement of the refractive index and the thickness of a transparent plate, based on the low coherence interferometry. This paper suggests that our method is applicable for birefringence measurement using unpolarized light source. Small birefringence of thin medium such as $\mathrm{LiTaO}_{3}$ crystal is measured with high accuracy, by introducing dispersion compensation into the low coherence interferometry.
\end{abstract}

キーワード : 低コヒーレンス光干渉、複屈折測定、分散補償

\section{1.はじめに}

発振スペクトルが半導体レーザに比ベて非常に広い、 スーパールミネッセントダイオード(SLD)などを光源とする 低コヒーレンス光干涉計は、信号光と参照光の光路長差が 極めて短い範囲でしか干涉しない特徽を生かして、光計測 分野で盛んに研究が進められている。我々は、SLDを光源 とするマイケルソン型低コヒーレンス干涉計と微動ステー ジを融合して、被測定物の屈折率nと厚されを同時精密測定 できる新手法を提案し、透明板および生体試料を用いた基 礎実験によってその有用性を実証してきた[1-6]。光らに、 屈折率が一様な等方性媒質だけでなく、複屈折媒質の位相 屈折率と群屈折率の同時測定法を提案してきた[7]。

従来より、面内複屈折を測定する手法として、古くは偏 光顕微鏡とバビネーソレイ工補償器を用る方法[8]、直交 2 周 波へテロダイン干涉計を用いる方法[9,10]、また共焦点顕微 鏡と低コヒーレンス光源を組み合わせる方法[11]などがあ る。しかし、いずれも試料の光学軸に対して光源の偏光方 向を一定角度で厳密に一致させる必要があり、さらに使用
波長の 2 分の 1 以上の比較的大きな複屈折測定が困難な方 式もある。

今回、試料厚の薄い开ンプルの複屈折を偏光制御なしで 精密に測定し、波長スペクトルの比較的広い低コヒーレン ス干涉計測で顕在化する、分散による測定精度の影䇺を実 験で確かめた。その結果をもとに分散補償を行うことによ り高精度の測定が行えたので報告する。

\section{2.測定原理 \\ $<2.1>$ 測定サンプル走查法}

測定サンプル走査法[5]による屈折率と厚さの同時測定系 を図1に示す。基本的にはマイケルソン型干涉計である。光 源は中心波長850nm、コヒーレンス長 $\Delta \mathrm{l}_{\mathrm{c}}(=12 \mu \mathrm{m}$ : 半值全幅 FWHM)のSLD(無偏光)である。SLD光はビーム径6 $\mathrm{mm} に コ$ リメートされビームスプリッタ(BS)で信号光(Z方向)と参照 光(X方向)に分割される。信号光はステッピングモータで駆 動されるステージ2上の被測定サンプル面に対物レンズ(x20) で集光される。サンプルからの反射光は再びBSを経て光検 
出器 (PD)で受光される。参照光はステッピングモータで駆 動されるステージ1上のミラで反射されBSを経てPDで受光 される。PZT面上に取り付けられた参照光ミラは、 $500 \mathrm{~Hz}$ の 正弦波信号を印加され微小振動しているため、位相変調さ れた参照光は信号光とPD上でへテロダイン検波される。検 波された干渉信号強度をPCで解析する。ステージ1,2の位置 分解能は $0.1 \mu \mathrm{m}$ であり、PC制御される。

測定は、まず(1)集光レンズを用いて被測定サンプルの前 面にSLD光を集光し、干涉計両アームの光路長が等しくな るよう、参照光ミラ(ステージ1)を移動する。ここから、(2) 被測定サンプル(ステージ2)を移動しサンプル後面に集光す る。再度、参照光ミラを移動して光路長を等しくする。

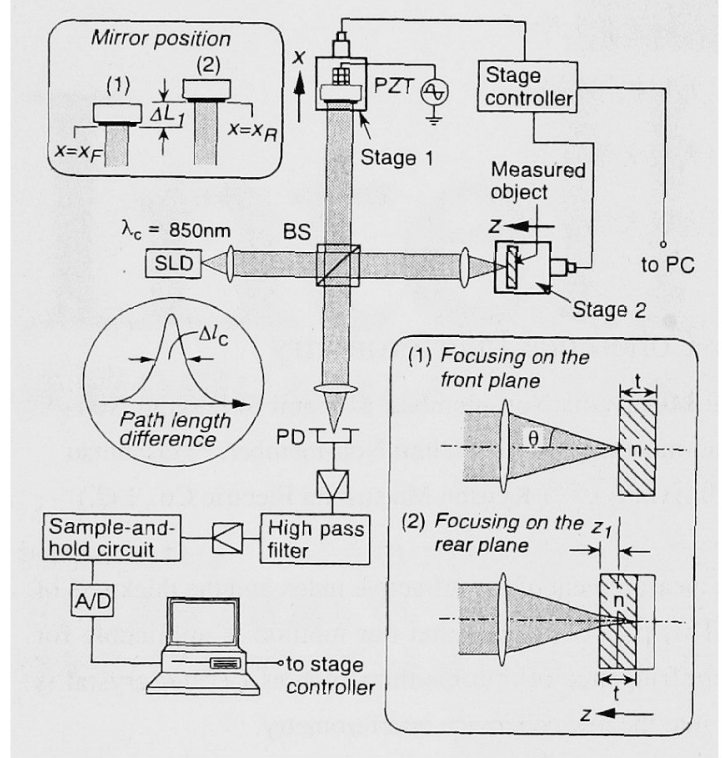

図1 測定システムの構成

Fig. 1. Configuration of the measurement system.

このとき、被測定サンプルの移動距離を $\mathrm{Z}_{1}$ 、参照光ミラの 移動距離を $\Delta \mathrm{L}_{1}$ とすると、被測定サンプルの屈折率nと厚さ $\mathrm{t}$ は $\mathrm{Z}_{1}$ と $\mathrm{L}_{1}$ の関係式が分かれば、 $\mathrm{n}$ と蛙分離して算出する ことが可能になる[1-5]。測定サンプルの前面においてスネ ルの法則を適用し次式が得られる。

$$
z_{1}=t \times \sqrt{\frac{1-\zeta^{2}}{n^{2}-\zeta^{2}}}
$$

ただし、 $=\sin \theta=$ N.A.でありレンズの開口数である。

一方、参照光ミラの移動距離 $\Delta \mathrm{L}_{1}$ はサンプル移動前後の光 路長差と等しいので、

$\Delta \mathrm{L}_{1}=\mathrm{n} \cdot \mathrm{t}-\mathrm{Z}_{1}$

の関係が成立する。(1)(2)式から tを消去すると、

$$
\mathrm{n}^{2}=\frac{1}{2}\left\{\zeta^{2}+\sqrt{\zeta^{4}+4\left(1-\zeta^{2}\right) \cdot\left(1+\frac{\Delta \mathrm{L}_{1}}{\mathrm{z}_{1}}\right)^{2}}\right\}
$$

という屈折率nを求める式が得られる。同時に、厚さtは(2) 式より、

$$
\mathrm{t}=\frac{\Delta \mathrm{L}_{1}+\mathrm{z}_{1}}{\mathrm{n}}
$$

で求められる。

\section{$<2.2>$ 複屈折の測定原理}

一軸性電気光学結晶などの複屈折媒質の面内複屈折を測 定する光学系について述べる。測定系の基本原理は2.1で述 べたものとほぼ同一である。図2に示すように、無偏光の SLDから放射される光線は任意の互いに直交する 2 つの直 線偏光成分の和として表される。

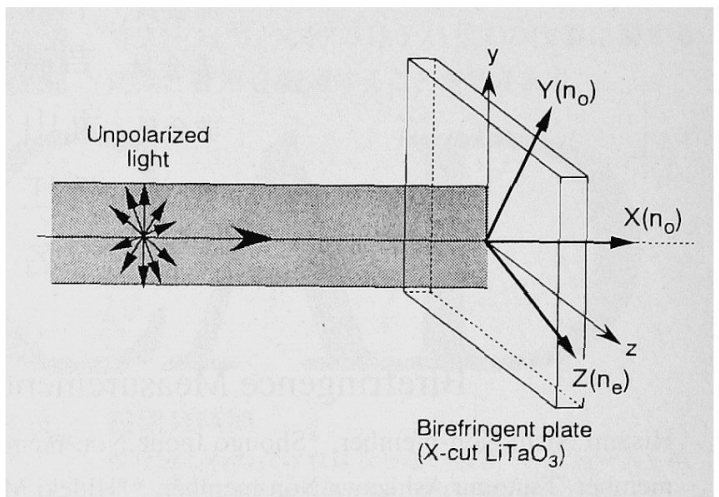

図2 複屈折の測定原理

Fig. 2. Principle of birefringence measurement.

被測定サンプルに入射した光線は複屈折材料のY軸、Z軸方 向の 2 偏光成分に分離する。そして、これら二つがそれぞ れ屈折率no(常光)、ne(異常光)を経験しながらサンプル内を 伝搬する。その結果、二つの直線偏光成分が通った光路長 に $\Delta \mathrm{n} \cdot \mathrm{t}=(\mathrm{no}-\mathrm{ne}) \cdot \mathrm{t}$ の差が生じる。低コヒーレンス干渉な ので、この差は偏光制御なしで求められる。なお、常光、 異常光のいずれか一方を偏光子で選択し測定することもで きるが、 2 度測定する必要がある。光路長差 $\Delta \mathrm{n} \cdot \mathrm{t}$ は、常光 と異常光の $\mathrm{Z}_{1} 、 \Delta \mathrm{L}_{1}$ の測定值 Zo、 $\Delta \mathrm{Lo} 、 \mathrm{Ze} 、 \Delta \mathrm{Le}$ を用いて

$$
\Delta \mathrm{n} \cdot \mathrm{t}=(\text { no-ne }) \cdot \mathrm{t}=(\Delta \mathrm{Lo}+\mathrm{Zo})-(\Delta \mathrm{Le}+\mathrm{Ze})
$$

で与えられる[7]。

なお、ここで測定される屈折率は光源の波長スペクトル が広く、低コヒーレンス状態なので群屈折率」[12]として求 められ[5-7]、 $\Delta \mathrm{ng}$ は群屈折率差である。

\section{3.複屈折の測定} $<3.1>\mathrm{LiNbO}_{3}$ の複屈折測定

2. 1 で述べた測定装置を用いて厚さ $\mathrm{t}=1028 \mu \mathrm{m}$ のカッ ト $\mathrm{LiNbO}_{3}$ の光路長差 $\Delta \mathrm{n} \cdot \mathrm{t}$ 測定した。ステージ1とステー ジ2を駆動して干渉信号のピーク位置を探すため、図 3 に示 すような信号群が得られる。Zo、 $\Delta \mathrm{Lo} 、 \mathrm{Ze} 、 \Delta \mathrm{Le}$ の測定結果 を(5)式に代入して実験値 $\Delta \mathrm{n} \cdot \mathrm{t}=94.0 \mu \mathrm{m}$ が得られた。なお、 $\mathrm{n}$ と測定精度は主に使用する微動ステージの位置決め精 度とサンプル厚社に依存し、1 $1 \mu \mathrm{m} /$ スップのステージを用 
いた場合には、 $\mathrm{t} \geqq 1 \mathrm{~mm} て ゙ 0.1 \%$ 以下の精度が期待できる。さ

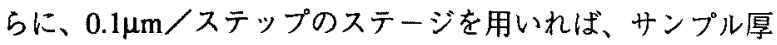
$\mathrm{t} \geqq 0.1 \mathrm{~mm}$ において $0.1 \%$ 精度を確保できる[7]。

さて、n,t同時測定法では 2 つのステージを駆動して信号 ピーク位置を探索するため測定時間がかかる。実用上、 $\Delta \mathrm{ng}$ あるいは $\Delta \mathrm{ng} \cdot$ tをを精度よく測定し、媒質の複屈折性を評価し たいという要求が高い。そこで、図1の干渉計において集 光レンズを取り除いてSLD平行光をXカット $\mathrm{LiNbO}_{3}$ 結晶板 に照射する。ステージ1または 2 のいづれかを走查すれ ば、極めて短時間で光路長差 $\Delta \mathrm{n}$. は、この1パススキャン測定法によるXカット $\mathrm{LiNbO}_{3}$ (図 3 と同一サンプル)の複屈折測定結果である。横軸は参照光ミ ラ(ステージ1)の移動量、緥軸はPDで検波された交流成分振

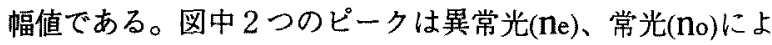

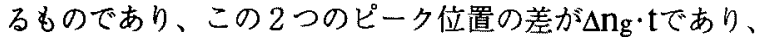
測定値 $94 \mu \mathrm{m}$ を得た。

一方、中心波長 $\lambda \mathrm{c}=850 \mathrm{~nm}$ における $\mathrm{LiNbO}_{3}$ の群屈折率理論 值はセルマイヤ方程式より、no= 2.3411、ne=2.2497であ るため[7]、光路長差の理論值は $\Delta \mathrm{n}_{\mathrm{g}} \cdot \mathrm{t}=(\mathrm{no}-\mathrm{ne}) \cdot \mathrm{t}=0.0914$ x $1028=94.0 \mu \mathrm{m}$ となり実験值 $94 \mu \mathrm{m}$ と一致した。今回使用し たSLDのコヒーレンス長 $\Delta \mathrm{lc}(=12 \mu \mathrm{m})$ に対して、 $\Delta \mathrm{ng} \cdot \mathrm{t} \gg$ $\Delta \mathrm{lc}$ なる条件を満たすため、異常光、常光による2つのピー クが十分分離した状態で観察された。
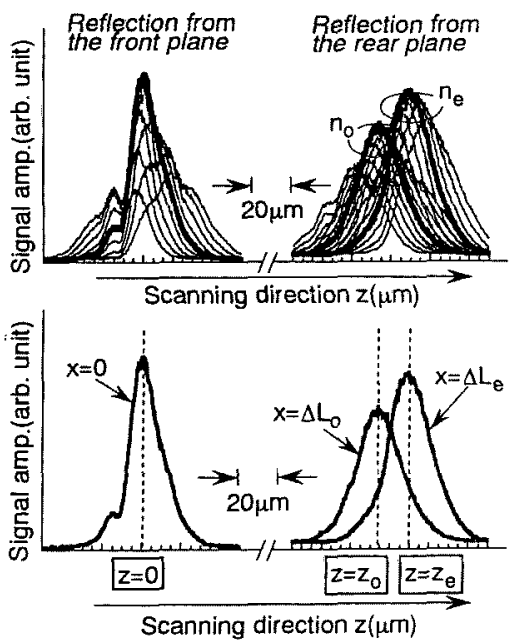

図3 サンプル走査法による $\mathrm{LiNbO}_{3}$ の光路長差測定信号

Fig.3. Detected signals of optical pass difference measurement for a $\mathrm{LiNbO}_{3}$ crystal by sample scanning method.

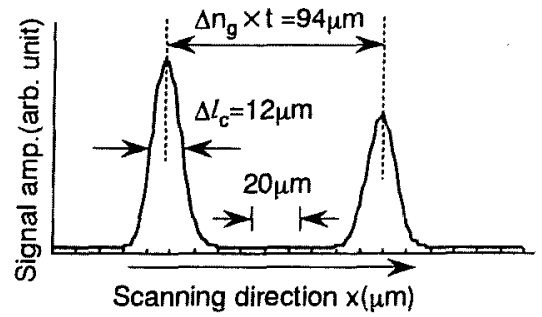

図4 1 パス走査法による $\mathrm{LiNbO}_{3}$ の光路長差

Fig. 4. Optical pass difference of a $\mathrm{LiNbO}_{3}$ crystal by one pass scanning method.

\section{$<3.2>\mathrm{LiTaO}_{3}$ 多重反射測定}

$\mathrm{LiNbO}_{3}$ は、屈折率差が $\Delta \mathrm{ng}_{\mathrm{g}}=\mathrm{no}_{\mathrm{O}}-\mathrm{ne}=0.0914$ となり比較 的複屈折の大きな媒質である。一方、 $\mathrm{LiTaO}_{3}$ は $\Delta \mathrm{ng}=\mathrm{n}_{\mathrm{O}}$ $\mathrm{ne}=-0.0051$ と $\mathrm{LiNbO}_{3}$ に比べて複屈折が小さい。よって、 薄いサンプルの場合、光路差が光源のコヒーレンス長より 短くなり、常光と異常光の干渉ピークが重なり明瞭に分蜼 できなくなる。そこで、四5に示すように、多重反射成分を 利用すると実効的にサンプル厚 $\mathrm{t}$ を反射回数倍に拡大でき る。

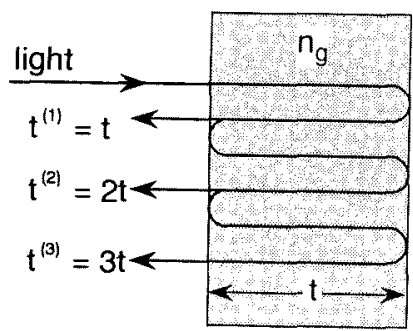

X-cut $\mathrm{LiTaO}_{3}$

図5多重反射を用いた光路長差の拡大 Fig. 5. Expansion of optical path difference by multiple reflections.

厚さ $\mathrm{t}=482 \mu \mathrm{m}$ のカット $\mathrm{LiTaO}_{3}$ に対してコヒーレンス長 $\Delta \mathrm{lc}=7.3 \mu \mathrm{m}$ の光源を用いて光路長に対する干涉信号振幅変 化を測定した。図6はそれぞれ、(a)サンプル後面（1 重反 射)、(b) 2 重反射、(c) 3 重反射、(d) 4 重反射での結果であ 万。測定は $(\mathrm{A})$ 直楾偏光による常光、異常光の個別測定 (細 線でno, ne と表示)、(B)無偏光による常光、異常光の同時測 定(太線でWithout polarizerと表示)の 2 種類を実施した。

(A)直線偏光測定は、無偏光の光源とBS間に偏光子を扦入 し回転させ、 $\mathrm{LiTaO}_{3}$ の主軸方向に偏光方向を一致させる。 さらに、90度偏光方向を回転させることにより、それぞれ 常光 $\left(\mathrm{n}_{\mathrm{o}}\right)$ と異常光(ne)を単独に測定できる。光路長、光路長 差、可干涉距離を表1にまとめた。これにより、光路長差が コヒーレンス長より短い場合でも測定できるが、偏光子を 回転させて 2 度測定する必要がある。可干渉距離は反射回 数の増加とともに広がっている。

(B)無偏光同時測定では 1 - 重反射において、光路長差 $4 \Delta \mathrm{ng} \cdot \mathrm{t}=4 \times(-0.0051) \times 482=-9.83 \mu \mathrm{m}$ となり、光路長差 がコヒーレンス長 $(\Delta \mathrm{lc}=7.3 \mu \mathrm{m})$ 程度のため、常光と異常光 との干渉ピークが明膫に分離していない。かろうじて、4

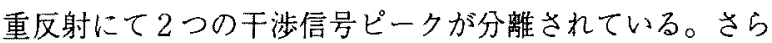
に、(A)直線偏光測定と対応する干涉信号ピーク位置は一致 しなくてはならないはずだが、両者に規則性のない「ずれ」 が生じている。 


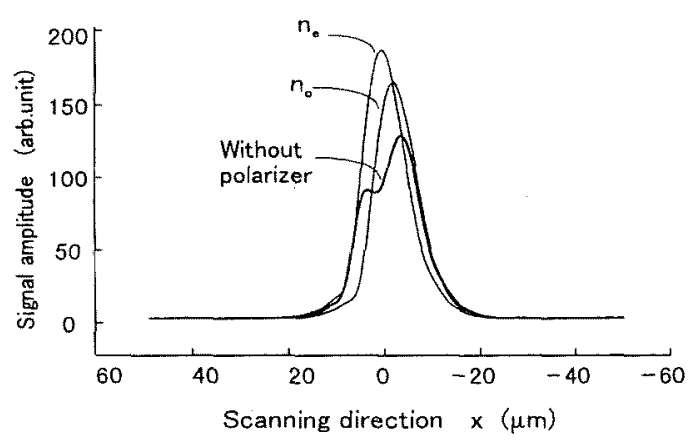

(a) Reflection from the back facet ( Single reflection ).

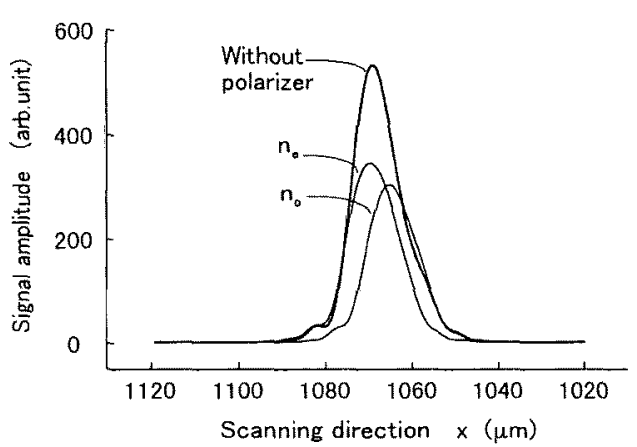

(b) Double reflections.

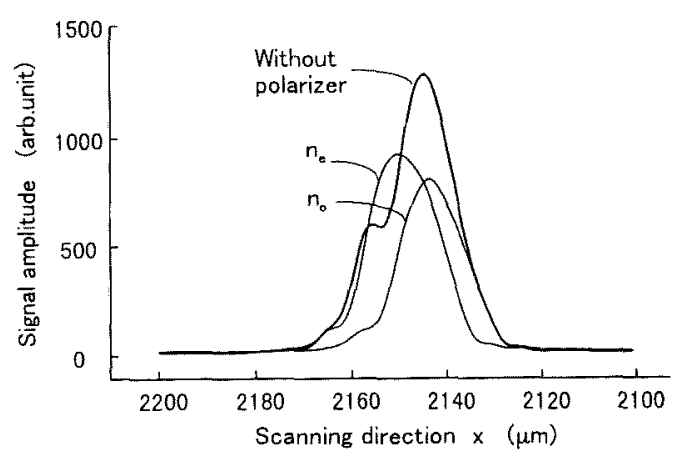

(c) Triple reflections.

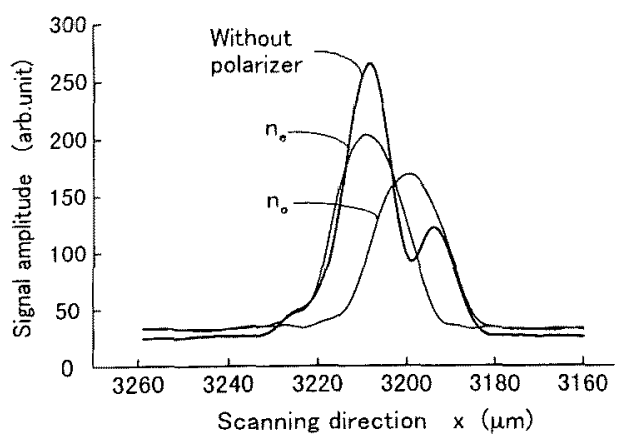

(d) Quadruplicate reflections.

図6 多重反射による $\mathrm{LiTaO}_{3}(\mathrm{t}=482 \mu \mathrm{m})$ の光路長差測定 Fig. 6. Optical pass difference measurement of $\mathrm{LiTaO}_{3}$ crystal $(\mathrm{t}=482 \mu \mathrm{m})$ by multiple reflection method.
表1。直線偏光によるXカット $\mathrm{LiTaO}_{3}$ の複屈折測定結果 Table 1. Birefringence of $\mathrm{X}$ cut $\mathrm{LiTaO}_{3}$ by linear polarizing measurement.

\begin{tabular}{|c|c|c|c|}
\hline & \multicolumn{2}{|c|}{ 光路長 } & 光路長差 \\
\hline & $n_{\mathrm{og}} \times t(\mu \mathrm{m})$ & $n_{\mathrm{eg}} \times t(\mu \mathrm{m})$ & $\Delta n_{\mathrm{g}} \times t(\mu \mathrm{m})$ \\
\hline 前面～後面 & 1072.9 & 1070.5 & 2.4 \\
\hline 後面～2重反射 & 1070.2 & 1067.5 & 5.1 \\
\hline 2重～3重 & 1079.5 & 1078.0 & 6.6 \\
\hline 3重 4重 & 1060.0 & 1056.6 & 10.0 \\
\hline & \multicolumn{2}{|c|}{ 可干涉距離 $\Delta l_{\mathrm{c}}(\mu \mathrm{m})$} & \\
\hline \multirow[t]{2}{*}{ 前面 } & \multicolumn{2}{|c|}{7.3} & $\begin{array}{l}n_{\mathrm{og}}=2.22268 \\
n_{\mathrm{eg}}=2.22778\end{array}$ \\
\hline & 常光線 & 異常光線 & \\
\hline 後面 & 10.3 & 10.3 & \\
\hline 2重反射 & 13.8 & 12.3 & \\
\hline 3重反射 & 17.1 & 15.2 & \\
\hline 4重反射 & 17.9 & 18.6 & \\
\hline
\end{tabular}

\section{4.波長分散の影響 \\ $<4.1>$ 波長分散のアンバランスによるコヒーレンス 長の広がり}

マイケルソン干渉計において、光源の波長スペクトルが 広がりを持つ場合、参照光アームと信号光アームのいずれ かに分散性媒質が存在し両アーム間の分散がアンバランス になると、干渉信号の振偪が低下するとともにピーク位置 がシフトすることが知られている[12]。そこで、複屈折が生 じいZカット $\mathrm{LiNbO}_{3}$ (厚さ $\mathrm{t}=515 \mu \mathrm{m}$ )を分散媒質として用 いて、2 重反射までのコヒーレンス長を測定した。表 $2 に$ 示すように可干渉距離 $\Delta \mathrm{lc}$ は、サンプル厚の增加とともに $7.8 \mu \mathrm{m}$ から $16.4 \mu \mathrm{m}$ へと増大する。同じく、低分散媒質であ る溶融石英（厚さ $\mathrm{t}=1022 \mu \mathrm{m}$ ）測定すると $\Delta \mathrm{lc}$ は $8.1 \mu \mathrm{m}$ から $7.8 \mu \mathrm{m}$ とほとんど変化しなかった。以上の結果より、干涉計 両アーム閒の波長分散のアンバランスが可干渉距離を広げ ている事が確想できた。

表2 分散媒質の等価厚み増大によるコヒーレンス長広がり Table 2. Coherent length spreading due to increasing of effective thickness of dispersive medium ( $\mathrm{Z}$ cut $\mathrm{LiNbO}_{3}$ ).

\begin{tabular}{|c|c|c|c|}
\hline \multicolumn{2}{|c|}{$n_{\mathrm{Og}} \times \mathrm{t}(\mu \mathrm{m})$} & \multicolumn{2}{c|}{$\Delta l_{\mathrm{c}}(\mu \mathrm{m})$} \\
\hline 前面 後面 & 1210.2 & 前面 & 7.8 \\
\hline 後面 2 2重反射 & 1213.6 & 後面 & 12.0 \\
\hline & & 2重反射 & 16.4 \\
\hline
\end{tabular}

\section{$<4.2>$ 波長分散の補償}

参照光ミラとBSの間に、分散補償材としてサンプルの $\mathrm{LiTaO}_{3}$ の 4 重反射伝搬距離 $4 \mathrm{t}$ とほぼ同等厚のZカット(複屈 折を生じない) $\mathrm{LiNbO}_{3}$ を挿入し測定を行った。当然のことな

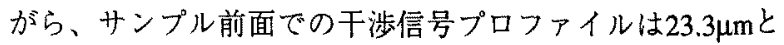
広がりがみられたが、4 重反射光による干涉信号プロフフ イルは図7に示すように、(B)無偏光測定で常光(no) と異常光

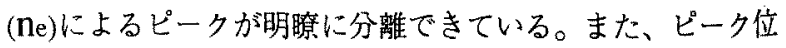
置は(A)直楾偏光測定のピーク位置 (図中細線)と一致した。 光路長差 $\Delta \mathrm{ng}_{\mathrm{g}} \times \mathrm{t}=9.6 \mu \mathrm{m}$ となり、偏光子を挿入して測定し 
た 1 重反射の結果 $\Delta \mathrm{ng} \cdot \mathrm{t}=2.4 \mu \mathrm{m}$ のちよど 4 倍になってい る。

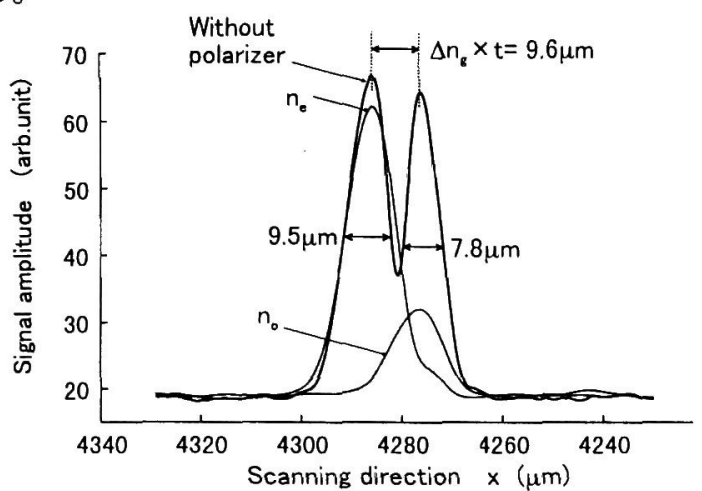

図7分散補償を行った 4 重反射による光路長差測定 Fig. 7. Optical pass difference measurement by quadruplicate reflections with dispersion compensation.

\section{5.まとめ}

低コヒーレンス干渉計を用いて、薄い電気光学結晶など の面内微小複屈折が測定可能な測定法を提案した。サイン プル厚が薄く光路長差が光源のコヒーレンス長以下の場合 には、サンプルの両面の多重反射を利用し実効的に光路長 差を拡大する手法を用いた。そのとき、信号、参照光両 アーム間の媒質の波長分散アンバランスによる干渉信号の 広がりは、サンプルと類似した分散值をもつ補償用媒質を もう一方のアームに挿入することにより、千渉ピーク幅が 広がる影響を大幅に改善されることを明らかにした。

具体例として、厚さ $\mathrm{t}=482 \mu \mathrm{m}$ の Xカット $\mathrm{LiTaO}_{3} の 4$ 重反 射測定において光源のコヒーレンス長と同等の光路長差 $\Delta \mathrm{ng}$ $\mathrm{x} 4 \mathrm{t}=9.6 \mu \mathrm{m}$ を明瞭に分離して測定できた。以上の結果よ り、偏光子を用いずとも無偏光多重反射に扔いて、微小複 屈折測定が可能となることを示した。

謝辞：日頃ご指導頂く阪大院工・西原浩教授、有益なご助 言を頂く阪大院工・伊東一良教授招よび大阪電通大・橋本 正弘教授、本研究をご援助頂く九州松下電器(株) デバイス 部門担当取締役・紙中伸征氏に感謝の意を表します。本研 究は文部省科学研究費基盤研究A(課題番号07555018)の援助 を受けた。記して謝意を表する。

(平成 10 年10月26日受付、平成11年3月8日再受付)

$$
\text { 参考文献 }
$$

[1] 近江,百石，田屟，春名：信学技報、OPE95-116 (1995).

[2] 田尻,白石,近江,春名：信学技報、OPE95-121 (1996).

[3] M.Ohmi,T.Shiraishi, H.Tajiri, M.Haruna:OFS'96,We3-40,Sapporo,May 1996

[4] 田尻,白石,近江,春名：第33回日本ME学会,䡴演36 (1996).

[5] 田尻,白石,近江,春名：応物光波センシング技術研究会,LST17-6 (1996).

[6] M.Haruna, M.Ohmi, H.Tajiri,T.Mitsuyama, H.Manyama, M.Hashimoto:

Optics Letter, Vol.23, No.12, pp.966-968 (1998) .

[7] 田尻,満山,近江,丸山,春名：信学技報, OPE96-116 (1997).

[8] 久保田,浮田,會田編：「光学技術ハンドブック」,p.297, 朝倉書占 (1975).

[9] 梅田,高和：信学論, C-I, J73-C-I, 10, p.652 (1990).

[10]佐藤,山本, 小穴,來,本問,高橋：第58回応物学術講演会予稿集, 4a-L-5 (1997).

[11] 深野,松本,山口：第58回応物学術講演会予稿集, 3p-L-13 (1997).

[12] 鶴田著: 「応用光学II 」,4-1-7項, 培風館 (1990).

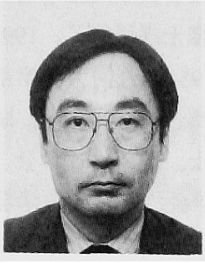

非会員） 1955年12月18日生。1978年3月大阪大 学工学部電子工学科卒業。1980年3月同大学大学 院工学研究科電子工学専攻博士前期課程修了。同 年4月～1997年3月日本板硝子(株) 勤務。1997年4 月大阪工業大学工学部電子工学科助教授、現在に 至る。屈折率分布型レンズ、光応用計測、画像計 測の研究に従事。工学博士。応用物理学会会員。 日本光学会会員。電子情報通信学会会員。

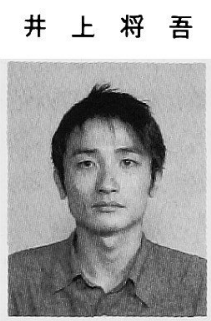

（非会員）1975年9月4日生。1998年3月大阪大学工 学部電子工学科卒。現在同大学工学研究科電子工 学専攻。低コヒーレンス光干渉計測の研究に従 事。

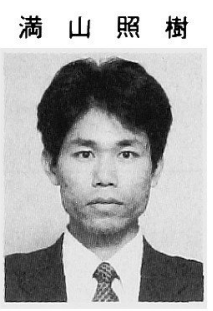

（非会員） 1973年11月1日生。1996年 3 月大阪大学 工学部電子工学科卒。1998年3月同大学工学研究 科電子工学専攻修了。同年4月 (株) 東京電力に入 社。在学中は低コヒーレンス光干涉計測の研究に 従事。

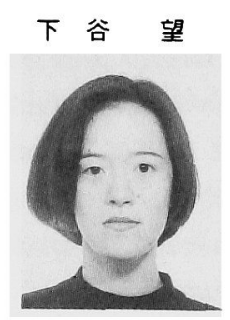

(非会員) 1976年2月28日生。1998年3月大阪工業 大学工学部電子工学科卒。同年4月テラメックス (株)に入社。在学中は低コヒーレンス光干涉計測 の研究に従事。

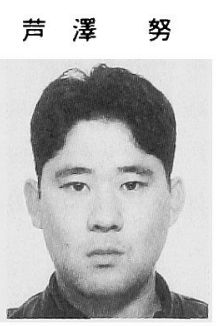

（非会員）1974年4月8日生.。1998年3月大阪工業 大学工学部電子工学科卒。同年4月に多多電線 (株) 入社。在学中は低コヒーレンス光干渉計測の 研究に従事。

丸山英樹

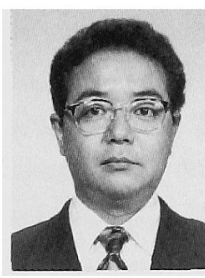

(非会員) 1963 年10月7日生。1984年3月国立久留 米高専工業化学科卒業。同年 4 月 1990年1月三 菱電線工業中央研究所に勤務、光ファイバ扔よび 光導波路の研究に従事。1990年2月九州松下電器 入社、現在に至る。1992年6月－1993年10月大阪 大学電子工学科西原研究室研究生。光応用計測、 光導波路デバイスの研究に従事。応用物理学会会 員。電子情報通信学会会員。 
近 江 雅 人 (非会員) 1966年9月17日生。1990年福井大学工学 部電気工学科卒、1992年大阪大学大学院工学研究 科電磁エネルギー工学尃攻・修士課程修了、1995 年同大学院博士課程修了、1995年4月同大医学部 助手、現在に至る。固体レーザ、生体光計測、医 用光学の研究に従事。工学博士。応用物理学会、 電子情報通信学会、日本ME学会、レーザー学会 の各会員。

春 名 正 光 (会員) 1945年11月20日生。1968年大阪大学工学 部電子工学科卒、1970年同大工学研究科電子工学 専攻・修士課程了、1973年同博士課程単位取得退 学、同年4月大大学工学部助手、1988年 4 月同助 教授、1994年4月同大医学部教授、現在に至る。 光導波路、レーザ応用プロセス、光センシングの 研究を経て、現在は医用光学; 光エレクトロニク ス、生体光計測の研究に従事。工博。電気学会、

電子情報通信学会、応用物理学会、日本ME学会、レーザ学会、IEEE の各会員 